\title{
Prophylactic anticoagulation in patients with glioblastoma or brain metastases and atrial fibrillation: an increased risk for intracranial hemorrhage?
}

\author{
Sina Burth ${ }^{1} \cdot$ Mona Ohmann ${ }^{1} \cdot$ Dorothea Kronsteiner $^{2} \cdot$ Meinhard Kieser $^{2} \cdot$ Sarah Löw $^{1} \cdot$ Lars Riedemann $^{1}$. \\ Mona Laible ${ }^{3} \cdot$ Anne Berberich $^{1} \cdot$ Katharina Drüschler $^{1} \cdot$ Timolaos Rizos $^{1} \cdot$ Antje Wick $^{1} \cdot$ Frank Winkler $^{1}$. \\ Wolfgang Wick ${ }^{1} \cdot$ Simon Nagel ${ }^{1}$ (D)
}

Received: 10 November 2020 / Accepted: 12 February 2021 / Published online: 5 March 2021

(c) The Author(s) 2021

\begin{abstract}
Purpose Patients with glioblastoma (GBM) or brain metastases (MET) and atrial fibrillation (AF) might be at an increased risk of intracranial hemorrhage ( $\mathrm{ICH})$ due to anticoagulation (AC). Our aim was to assess this risk.

Methods Our institution's database (from 2005 to 2017) was screened for patients with GBM or MET and AF with an indication for $\mathrm{AC}$ according to their $\mathrm{CHA}_{2} \mathrm{DS}_{2} \mathrm{VASc}$ stroke risk score $(\geq 2)$. Required follow-up was at least 3 months. AC was either performed with heparins, phenprocoumon or non-Vitamin $\mathrm{K}$ antagonist oral anticoagulants. Applying the propensity score approach, patient cohorts (matched according to primary tumor, age, sex) were generated (GBM [or MET] with $\mathrm{AF} \pm \mathrm{AC}, \mathrm{GBM}$ [or MET] without AF/AC, no GBM [or MET] but AF on AC). ICH was defined as clinical deterioration caused by new blood on imaging. A log rank test was performed to compare the risk for ICH between the three groups. Results In total, 104 patients were identified of which 49 with GBM (37\% on AC) and 37 with MET (46\% on AC) were successfully matched. Median follow up was 8.6 and 7.2 months, respectively. ICH occurred in $10.2 \%$ of GBM + AF and $12.2 \%$ GBM-AF, whereas $8 \%$ of patients with AF on AC suffered ICH $(\mathrm{p}=0.076) .13 .5 \%$ of patients with MET + AF had ICHs, in the controls it was $16 \%$ for MET-AF and $8 \%$ for AF on AC $(p=0.11)$.

Conclusion AC did not seem to influence the incidence of $\mathrm{ICH}$ in patients with glioblastoma or brain metastases within follow up of just under 9 months.
\end{abstract}

Keywords Intracranial hemorrhage $\cdot$ Glioblastoma $\cdot$ Metastasis $\cdot$ Anticoagulants $\cdot$ Atrial fibrillation

\section{Introduction}

Glioblastomas generally occur later in life with a median age at diagnosis of 65 years [1], whereas the incidence proportion for brain metastases varies depending on the primary tumor ranging between 20 and 39 years for breast

Simon Nagel

Simon.Nagel@med.uni-heidelberg.de

1 Department of Neurology, Heidelberg University Hospital, Im Neuenheimer Feld 400, 69120 Heidelberg, Germany

2 Institute of Medical Biometry and Informatics, Heidelberg University Hospital, Im Neuenheimer Feld 130.3, 69120 Heidelberg, Germany

3 Department of Neurology, Ulm University Hospital, Oberer Eselsberg 45, 89081 Ulm, Germany cancer, 40-49 years for lung cancer and 50-59 years for melanoma, renal and colorectal cancer [2]. Elderly patients often have comorbidities that require management during cancer treatment. One is the need for anticoagulation (AC) to prevent systemic embolism due to atrial fibrillation (AF) which has been reported to be present in $1.4 \%$ of patients with glioblastoma [3]. With an increasing prevalence of AF with older age, $3.8 \%$ of people over 60 years suffer from AF and might be recommended to be anticoagulated due to a $\mathrm{CHA}_{2} \mathrm{DS}_{2} \mathrm{VASc}-\mathrm{Score}$, which identifies the risk of a person with AF to develop an ischemic stroke, of $\geq 2$ [4].

However, anticoagulation in patients with brain tumors might put them at increased risk of intracranial hemorrhage (ICH) both in the perioperative period and in the subsequent phase of adjuvant treatment.

To date, most studies have examined the risk of $\mathrm{ICH}$ in the context of venous thromboembolism (VTE) which 
occurs frequently in patients with glioblastoma (15-30\% of patients) [5-8] and brain metastases (four- to sevenfold higher risk [9]).

For patients with glioblastoma, anticoagulation is only administered in about $60 \%$ when indicated [6]. When anticoagulated for VTE, incidences of ICH vary between $2 \%$, $7 \%$ and $4.7 \%$ in patients with glioblastoma in literature [3, $10,11]$. In one retrospective analysis patients $(n=133)$ with high-grade glioma on anticoagulation with enoxaparin were found to have a threefold increased risk of ICH (14.7\% vs $2.5 \%$ ) [12]. A recent meta-analysis confirms that especially patients with glioma have a threefold increased risk for ICH when on therapeutic anticoagulation for VTE [8]. Herein, the overall rates of ICH varied from 1.9 to $23 \%$ with a fatality rate of less than $1 \%$ [8].

In contrast, the risk for ICH is considered to vary for patients with brain metastases depending on the primary tumor. Patients with melanoma, choriocarcinoma, thyroid carcinoma, hepatocellular carcinoma and renal cell carcinoma were reported to be at particularly high risk $[13,14]$. Recently, studies have found that anticoagulation did not influence the incidence of ICH for patients with metastatic melanoma, renal cell carcinoma or lung cancer $[8,15,16]$, although the general risk was still fourfold increased for melanoma and renal cell carcinoma compared to lung cancer. According to another recent review, therapeutic anticoagulation in patients with treated brain metastases seems to have an acceptable risk of $<1 \%[17,18]$.

In contrast to indications for therapeutic anticoagulation such as VTE, anticoagulation for AF is administered preventively to decrease the risk of stroke which is determined by the $\mathrm{CHA}_{2} \mathrm{DS}_{2} \mathrm{VASc}$-Score. In this clinical scenario, stroke is only a potential, future risk but anticoagulation might increase the risk of bleeding in the present. Contrarily, a therapeutic anticoagulation for deep vein thrombosis or pulmonary embolism is inevitable as these conditions have to be treated despite the patients' comorbidities. This study aims to assess the proportion of preventive full anticoagulation and the incidence of ICH by retrospectively analyzing two cohorts of patients with glioblastoma and brain metastases that also suffered from AF. Respective controls were cohorts of patients with glioblastoma or brain metastases without anticoagulation and of patients with AF on anticoagulation but without brain tumors.

\section{Methods}

Inclusion of patients into this analysis is covered by a local Heidelberg ethics vote (No. S307/2019). To distinguish both a potential risk for ICH due to a brain tumor and the bleeding risk caused by anticoagulation we defined three groups. For the first group, our institution's database
(2005-2017) was screened for patients with a main diagnosis of a CNS tumor (ICD-codes C70.0 to C72.9) or CNS metastases (ICD-codes C79.3 to C79.4) that additionally suffered from AF (ICD-codes I48.0 to i48.9), were on continuous anticoagulation (ICD Z92.1) or had bleeding diatheses due to anticoagulation (ICD-codes D68.33 to D68.39). This group was named glioblastoma plus $\mathrm{AF}(\mathrm{GBM}+\mathrm{AF})$ and metastases plus $\mathrm{AF}(\mathrm{MET}+\mathrm{AF})$, respectively. The study was designed as an intention to treat study meaning that all of the patients in GBM $+\mathrm{AF}$ and MET + AF had an indication to be anticoagulated. The second group which was one of the control groups was acquired accordingly (2007-2017) using only the ICDcodes for glioblastoma $(\mathrm{N}=628)$ or brain metastases $(\mathrm{N}=434)$. This group ought to provide data on the baseline bleeding risk for patients with brain tumors that were not anticoagulated. The cohorts were called glioblastoma without AF (GBM-AF) and brain metastases without AF (MET-AF). Follow-up in all these groups was required until date of death or for at least 3 months. The third control group consisted of an already existing cohort of 90 patients from our institution with stroke or TIA with AF on anticoagulation [19] and a follow-up of 3 years. This group factors in the bleeding risk for patients that are anticoagulated but have no intracerebral neoplasm.

From the initial screening, we identified 166 patients in the glioblastoma cohort (GBM + AF). Of these patients, 55 had to be excluded as they did not suffer from AF but were anticoagulated because of TVT, pulmonary embolism or other reasons. 25 patients had insufficient data or followup and 25 patients had a CNS tumor other than glioblastoma, leaving 61 patients that entered the matching process (Fig. 1).

Accordingly, 147 patients with brain metastases were identified (MET + AF). 51 patients were excluded as they were anticoagulated for reasons other than AF, 43 patients had insufficient data or follow-up and 10 patients had no solid metastases but suffered from meningeal disease or leukemia, leaving 43 patients that entered the matching process (Fig. 1).

A 2-step matching procedure was done using the propensity score approach [20]. The propensity score was estimated by logistic regression with group as dependent variable. The matching was done on the logit of the propensity score using a caliper of 0.2 of the standard deviation of the logit of the propensity score [20]. In a first matching step, 61 patients with glioblastoma $(\mathrm{GBM}+\mathrm{AF})$ and 43 patients with metastases (MET $+\mathrm{AF}$ ) were matched to their control groups GBM-AF $(\mathrm{N}=628)$ and MET-AF $(\mathrm{N}=434)$ according to age, sex and primary tumor. In a second matching step, the vascular control group (stroke with AF on AC) was used yielding 49 triplets of patients for the glioblastoma group and 37 triplets of patients for the metastases 
Fig. 1 Selection process for patient cohorts. $\mathrm{AC}=$ full anticoagulation (receiving phenprocoumon, non-Vitamin $\mathrm{K}$ antagonist oral anticoagulants or at least enoxaparin $40 \mathrm{mg}$ twice daily). $A F$ atrial fibrillation

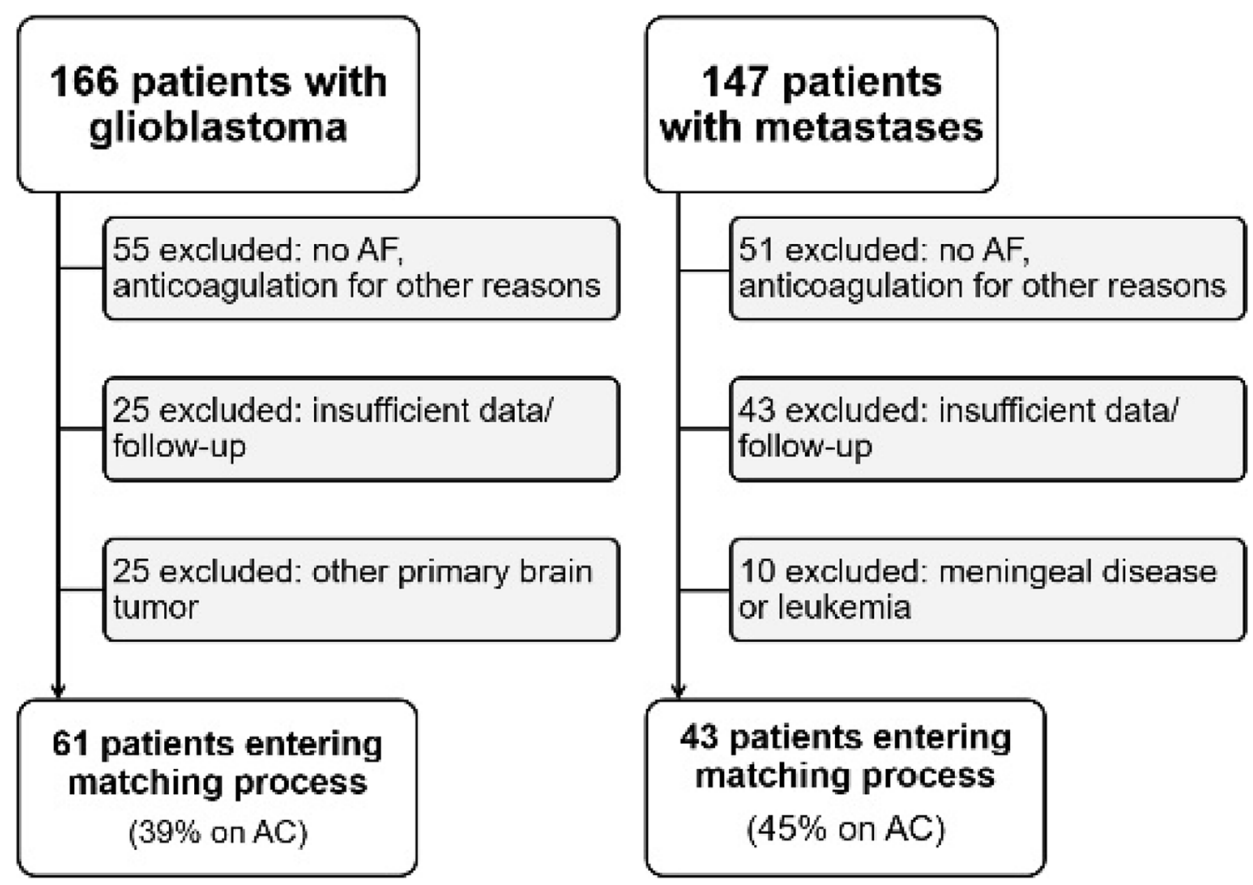

group matched according to age, sex, primary tumor and $\mathrm{CHA}_{2} \mathrm{DS}_{2}$ VASc-Score (Fig. 2).

For these patients, data was completed including age at diagnosis (defined as first detection of glioblastoma or brain metastases on imaging), sex, $\mathrm{CHA}_{2} \mathrm{DS}_{2} \mathrm{VASc}-\mathrm{Score}$, date of progression according to RANO criteria [21] and/ or death (censored to the date of last follow up at an outpatient or inpatient presentation), methylation status of the MGMT-promoter and Karnofsky performance index where applicable, type of resection (biopsy, subtotal or total), adjuvant therapy regimen including chemotherapy, radiotherapy, both or palliative care and use of VEGF-receptor (vascular endothelial growth factor) inhibitors such as bevacizumab, which may increase the risk of bleeding [22], type and dose of anticoagulation and detailed information about bleeding and ischemic events. Full anticoagulation was defined as receiving phenprocoumon according to INR, receiving a non-Vitamin $\mathrm{K}$ antagonist oral anticoagulant or receiving heparin (dosage of at least $40 \mathrm{mg}$ twice daily). Prophylactic anticoagulation with a heparin (i.e. VTE prophylaxis) consisted of enoxaparin $40 \mathrm{mg}$ once daily. Anticoagulation was documented if it was noted as a regular, long term
Fig. 2 Matching process in 2 steps applying the propensity score. $A F$ atrial fibrillation

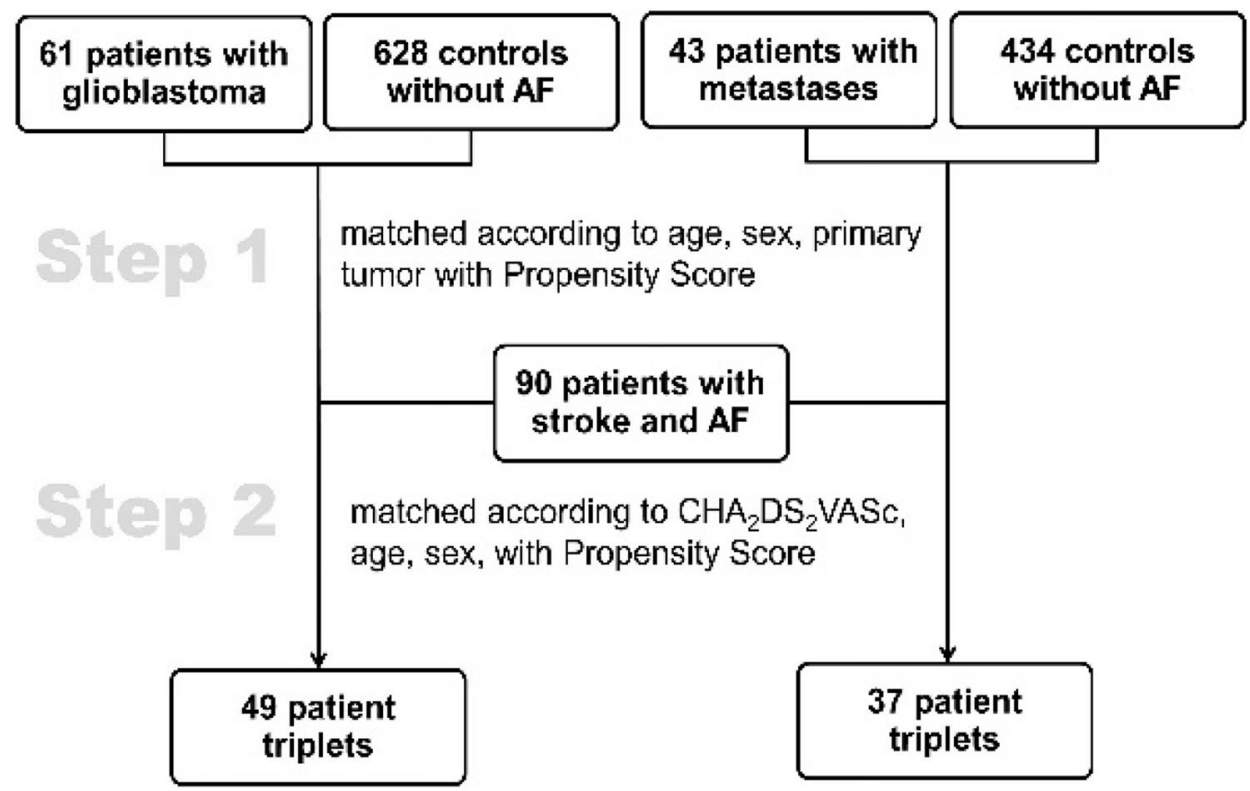


medication in the patient's admission/discharge medication plan. Bleeding events were primarily subclassified into microbleeds, locally contained or space occupying lesions (including midline shift or extension into the ventricles) as visible or described in the CT/MRI-reports (Fig. 3). Microbleeds were defined as punctate, homogeneous, rounded, hypointense lesions in the parenchyma that are smaller than 5-10 $\mathrm{mm}$ according to Kidwell, Wintermark et al. [23] and not counted as true bleeding events (slice thickness of our susceptibility weighted imaging was $2.5 \mathrm{~mm}$ ). A separate category was included determining if the bleeding was clinically symptomatic with an altered level of consciousness, a new neurologic deficit, headache or nausea or warranted surgical treatment ("symptomatic", sICH) or an incidental finding on routine imaging ("minor"), as the presence of contained, localized and small bleedings into a lesion would not be considered a harmful effect of the anticoagulation to the patient. Also, detailed follow-up imaging to detect such bleeds (in contrast to clinical information) was not available for all patients. Furthermore, the type of intracranial bleeding was noted (parenchymal, subdural, epidural, subarachnoid) and extracranial bleeding events were also documented (gastrointestinal etc.). Data was obtained as to whether the bleeding was present at the time of primary diagnosis or occurred perioperatively, spontaneous without anticoagulation or under anticoagulation. Ischemic events were subclassified into perioperative or spontaneous ischemic strokes, sinus thrombosis, pulmonary embolism, deep vein thrombosis or other extracranial ischemia such as bowel ischemia.

As the primary endpoint, the event of a clinically relevant symptomatic intracranial hemorrhage (sICH, yes/no) was chosen. Log-rank tests were performed to compare the groups concerning their bleeding events including the time until the event occurred to adjust for different follow-up times. For post-hoc (pairwise-) analysis of bleeding events over time Dunnett tests were used to adjust the p-values for multiple testing. Additionally, a mixed logistic regression was performed to examine the group (treatment vs. controls) as a possible explaining variable for the bleeding risk and using a random effect to take the matching procedure into account. Finally, McNemar tests were performed to compare the rate of strokes and bleeding events for patients with intracranial lesions and AF. Patient, disease, and therapy characteristics were analyzed descriptively using absolute and relative frequencies for categorical variables and median, first and third quartiles and range for continuous variables. Since this is an exploratory analysis $\mathrm{p}$ values are of descriptive nature. All statistical analyses were done using $\mathrm{R}$ version 6.3.3 [24].

\section{Results}

The clinical characteristics of the cohorts are illustrated in Table 1. For the control group of patients with stroke and AF these were already published [19].

Five (10.2\%) of patients with glioblastoma with AF suffered a sICH within a median follow-up time of 8.6 months (range 1-72 months). Two bleeds occurred under anticoagulation (40\%), two perioperatively (40\%) and one spontaneously without anticoagulation (20\%). Looking at the different subgroups within the cohort of GBM $+\mathrm{AF}, \mathrm{N}=18$ patients (37\%) received full anticoagulation (i.e. Enoxaparin $40 \mathrm{mg}$ 1-0-1, Phenprocoumon according to INR or a NOAC) and two sICHs occurred yielding a bleeding rate of $11 \%$. In the subgroup that received anticoagulation for the prevention of VTE (i.e. Enoxaparin $40 \mathrm{mg} 0-0-1, \mathrm{~N}=15,31 \%$ ) or where anticoagulation was not administered or paused $(\mathrm{N}=16,32 \%)$ three sICHs occurred yielding a bleeding rate of $9.7 \% .49 \%$ of patients died within the follow-up period.
Fig. 3 a Localized bleeding in a left cerebellar metastasis of a 63 -year old male (lung cancer, on Rivaroxaban) presenting with a deterioration of gait. $\mathbf{b}$ Spontaneous right occipital ICH in a 74-year-old patient with melanoma. He presented with headache, nausea and vomiting and did not receive anticoagulation
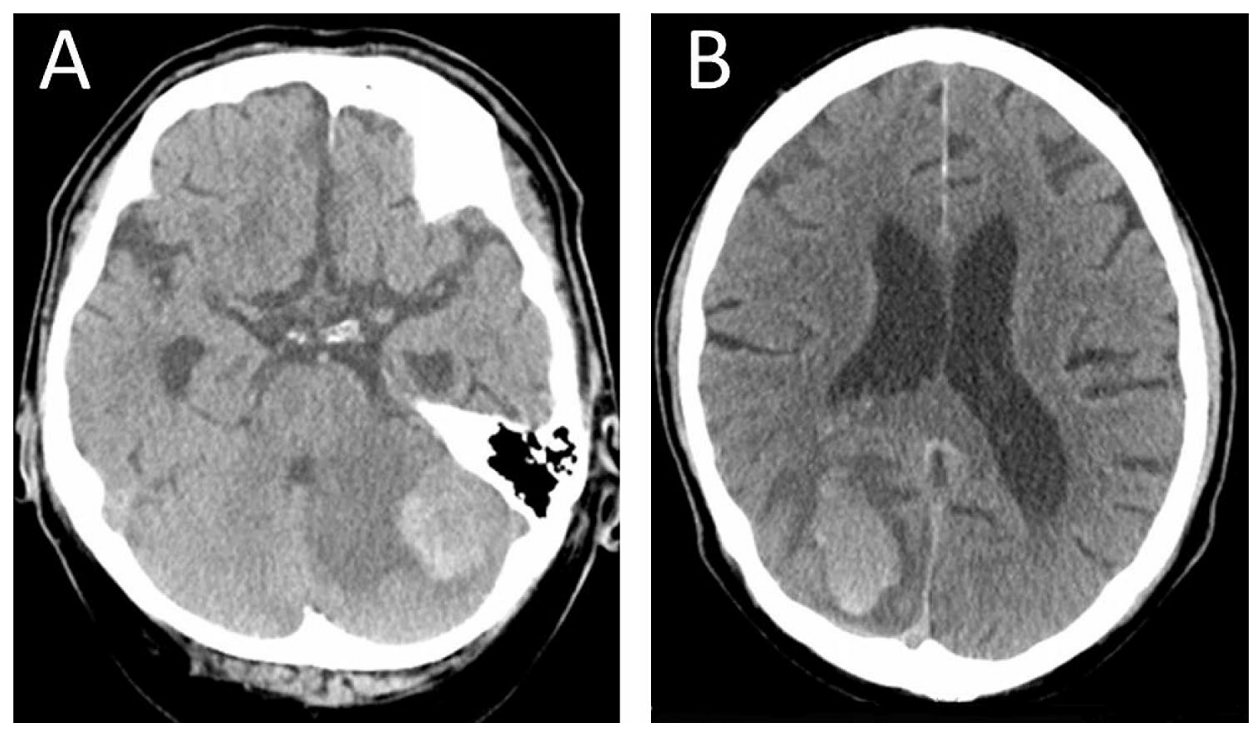
Table 1 Descriptive statistics of the main patient cohorts

\begin{tabular}{|c|c|c|c|c|c|}
\hline Variable & $\mathrm{GBM}+\mathrm{AF}(\mathrm{N}=49)$ & GBM-AF (N=49) & Variable & $\mathrm{MET}+\mathrm{AF}(\mathrm{N}=37)$ & MET-AF $(\mathrm{N}=37)$ \\
\hline Median age (range; $\mathrm{q}_{1} / \mathrm{q}_{3}$ ) & $71(37-84 ; 69 / 76)$ & $70(51-90 ; 67 / 74)$ & Median age (range; $\mathrm{q}_{1} / \mathrm{q}_{3}$ ) & $71(39-81 ; 63 / 74)$ & $71(33-83 ; 65 / 77)$ \\
\hline Sex (male/female) & $76 \% / 24 \%$ & $78 \% / 22 \%$ & Sex (male/female) & $67 \% / 33 \%$ & $67 \% / 33 \%$ \\
\hline Resection & & & Resection & & \\
\hline Biopsy & $12(24 \%)$ & $4(8 \%)$ & Yes & $21(57 \%)$ & $20(54 \%)$ \\
\hline Subtotal & $19(39 \%)$ & $12(24 \%)$ & No & $16(43 \%)$ & $17(46 \%)$ \\
\hline Total & $18(37 \%)$ & $32(65 \%)$ & & & \\
\hline Adjuvant therapy & & & Adjuvant therapy & & \\
\hline Stupp & $38(78 \%)$ & $33(67 \%)$ & RT alone & $22(59 \%)$ & $20(54 \%)$ \\
\hline Stupp + BEV & $6(12 \%)$ & $15(31 \%)$ & Chemo $\pm \mathrm{RT}$ & $10(27 \%)$ & $11(30 \%)$ \\
\hline Palliative & $5(10 \%)$ & $1(2 \%)$ & Palliative & $5(14 \%)$ & $6(16 \%)$ \\
\hline Anticoagulation & & & Anticoagulation & & \\
\hline On full $\mathrm{AC}$ & $18(37 \%)$ & None & & $17(46 \%)$ & None \\
\hline NOAC & $9(18 \%)$ & & & $6(16 \%)$ & \\
\hline Phenprocoumon & $1(2 \%)$ & & & $2(54 \%)$ & \\
\hline Heparin & $8(16 \%)$ & & & $9(24 \%)$ & \\
\hline Prophylactic AC/heparin & $15(31 \%)$ & & & $7(19 \%)$ & \\
\hline None & $16(33 \%)$ & & & $13(35 \%)$ & \\
\hline $\mathrm{ICH}$ & & & $\mathrm{ICH}$ & & \\
\hline Yes & $8(16 \%)$ & $7(14 \%)$ & & $5(14 \%)$ & $7(19 \%)$ \\
\hline No & $41(84 \%)$ & $42(86 \%)$ & & $32(86 \%)$ & $30(81 \%)$ \\
\hline Clinical presentation & & & Clinical presentation & & \\
\hline Silent (minor) & $3(6 \%)$ & $1(2 \%)$ & & 0 & $1(3 \%)$ \\
\hline $\begin{array}{l}\text { Symptomatic (sICH) } \\
\text { (primary endpoint) }\end{array}$ & $5(10.2 \%)$ & $6(12.2 \%)$ & & $5(13.5 \%)$ & $6(16 \%)$ \\
\hline Extend of bleed & & & Extend of bleed & & \\
\hline Local & $2(25 \%)$ & $5(71 \%)$ & & $3(60 \%)$ & $6(86 \%)$ \\
\hline Space-occupying & $6(75 \%)$ & $2(29 \%)$ & & $2(40 \%)$ & $1(14 \%)$ \\
\hline Localisation & & & Localisation & & \\
\hline Parenchymal & $5(20.0 \%)$ & $6(86 \%)$ & & $5(100 \%)$ & $6(86 \%)$ \\
\hline Subdural & $2(50.0 \%)$ & $1(14 \%)$ & & 0 & 0 \\
\hline Other intracranial & $1(30.0 \%)$ & 0 & & 0 & $1(14 \%)$ \\
\hline Extracranial & 0 & 0 & & 1 & 0 \\
\hline Surgical evacuation of ICH & $4(8 \%)$ & $3(6 \%)$ & $\begin{array}{l}\text { Surgical evacuation of } \\
\text { ICH }\end{array}$ & $1(3 \%)$ & $1(3 \%)$ \\
\hline $\mathrm{CHA}_{2} \mathrm{DS}_{2} \mathrm{VASc}$ & 3 & l & $\mathrm{CHA}_{2} \mathrm{DS}_{2} \mathrm{VASc}$ & 3 & I \\
\hline \multirow[t]{7}{*}{ Median KPI } & 70 & 70 & Median KPI & 80 & I \\
\hline & & & Primary tumor & & \\
\hline & & & Lung & $19(51 \%)$ & $20(54 \%)$ \\
\hline & & & Breast & $5(14 \%)$ & $3(8 \%)$ \\
\hline & & & Melanoma & $3(8 \%)$ & $6(16 \%)$ \\
\hline & & & Kidney & $3(8 \%)$ & $1(3 \%)$ \\
\hline & & & Other & $7(19 \%)$ & $7(19 \%)$ \\
\hline
\end{tabular}

$A C$ anticoagulation, $A F$ atrial fibrillation, $B E V$ Bevacizumab, $G B M$ glioblastoma, $I C H$ intracranial hemorrhage, $K P I$ Karnofsky Performance Index, $M E T$ brain metastases, $N$ number of patients per cohort, $N O A C$ non-vitamin $\mathrm{K}$ antagonist oral anticoagulants, $q_{1}$ first quartile, $q_{3}$ third quartile, $R T$ radiotherapy, $s I C H$ symptomatic ICH, Stupp therapy regimen according to Stupp et al. (Temozolomide plus radiation)

Median $\mathrm{CHA}_{2} \mathrm{DS}_{2} \mathrm{VASc}$-Score was 3. Five patients suffered a stroke (10\%), one patient a sinus thrombosis (2\%).

In the control group without $\mathrm{AF}$, six patients $(12.2 \%$, two spontaneously without anticoagulation and four perioperatively; $33 \%$ and $67 \%$ ) had sICH within a median follow-up time of 14.9 months (range 7-97 months). The log rank test comparing all three groups revealed no difference of ICH between the three groups ( $p=0.076)$, neither did the 
Dunnet test for the comparison of the groups glioblastoma with $\mathrm{AF} /$ without $\mathrm{AF}(\mathrm{p}=0.991)$ and glioblastoma with $\mathrm{AF} /$ vascular control group $(\mathrm{p}=0.123)$ (Table 2, Kaplan-Meier curves are provided in Online Resource 1). In the logistic regression model the group did not seem to influence the event $(\mathrm{p}=0.749$ for $\mathrm{GBM}+\mathrm{AF}$ vs. GBM-AF and $\mathrm{p}=0.465$ for $\mathrm{GBM}+\mathrm{AF}$ vs. stroke with AF on AC). Hence, here anticoagulation had no effect on the incidence of ICHs in patients with glioblastoma. McNemar test showed no difference in the rate for bleeding events and strokes for patients with glioblastoma and AF $(\mathrm{p}=1.0)$.

In the patient cohort with brain metastases and $\mathrm{AF}$, a symptomatic ICH occurred in five patients (13.5\%) within a median follow-up time of 7.2 months (range 0.5 to 143 months). Three bleeds (60\%) occurred under anticoagulation, one with initial diagnosis $(20 \%)$ and one spontaneously without anticoagulation (20\%). Looking at the different subgroups within the cohort of MET $+\mathrm{AF}, \mathrm{N}=17$ patients (46\%) received full anticoagulation (i.e. Enoxaparin $40 \mathrm{mg}$ 1-0-1, Phenprocoumon according to INR or a NOAC) and three sICHs occurred yielding a bleeding rate of $17.6 \%$. In the subgroup that received anticoagulation for the prevention of VTE (i.e. Enoxaparin $40 \mathrm{mg} 0-0-1, \mathrm{~N}=7,19 \%$ ) or where anticoagulation was not administered or paused $(\mathrm{N}=13,35 \%)$ two sICHs occurred yielding a bleeding rate of $10 \% .51 \%$ of patients died within the follow-up period. Median $\mathrm{CHA}_{2} \mathrm{DS}_{2} \mathrm{VASc}$-Score was 3. Three patients suffered a stroke (8\%), one patient additionally developed a pulmonary embolism (2.7\%).

For the control group without AF incidence of sICH was $16.2 \%$ (total of 6 patients) within 8.4 months (range 0.25 to 62 months). Four bleeds occurred spontaneously (67\%) and two with the initial diagnosis (33\%). The log rank test comparing all three groups revealed no considerable difference of ICH between the three groups $(p=0.11)$, neither did the Dunnet test for the comparison of the groups brain metastases with $\mathrm{AF} /$ without $\mathrm{AF}(\mathrm{p}=0.765)$ and brain metastases with $\mathrm{AF} / \mathrm{vascular}$ control group $(\mathrm{p}=0.253)$ (Table 2, Kaplan-Meier curves are provided in Online Resource 2). In the logistic regression model the group did not seem to influence the event $(p=0.499$ for MET + AF vs. MET-AF and $\mathrm{p}=0.692$ for MET $+\mathrm{AF}$ vs. stroke with AF on AC). McNemar test showed no difference in the rate for bleeding events and strokes for patients with brain metastases and $\operatorname{AF}(\mathrm{p}=1.0)$.

\section{Discussion}

This study specifically addressed the risk/benefit assessment of anticoagulation for patients with brain tumors and AF. The existing literature primarily focuses on examining therapeutic anticoagulation for venous thromboembolism which has been shown to occur more often in patients with cancer [5-9]. While the latter is a therapeutic anticoagulation, anticoagulation for $\mathrm{AF}$ is prophylactic and one might hesitate more due to a perceived higher intracranial bleeding risk in GBM and MET patients.

Our data suggest that anticoagulation neither increases the risk for ICH in glioblastoma patients nor in patients with brain metastases within the given median follow up of 8.6 and 7.2 months. At least for the former group, a threefold increased risk has been reported [8]. At $10.2 \%$ for the patients with glioblastoma and $\mathrm{AF}$ and $12.2 \%$ for the control group, the incidence of ICH lies within the reported range of $1.9-23 \%$ [8]. Our analysis was planned as intention to treat study, but since this was a retrospective analysis, it was not always clear why patients did not receive (oral) anticoagulation in the end. Still, the bleeding rates in the subgroups of patients on full anticoagulation were similar to these of the whole collective ( $11 \%$ vs. $10.2 \%$ for GBM+AF and $18 \%$ vs. $13.5 \%$ for $\mathrm{MET}+\mathrm{AF})$.

In the group $\mathrm{GBM}+\mathrm{AF}, 12 \%$ of patients received bevacizumab, in the control group GBM-AF it was 33\%. Due to the design of our study, we were not able to correct for a therapy with bevacizumab, which is known to increase the risk for bleeding complications [25]. For patients with brain metastases, our data is comparable to studies examining anticoagulation for venous thromboembolism. The proportion of ICH was slightly increased for patients with melanoma (accounting for $45 \%$ of all $\mathrm{ICH})$ compared to their representation within the cohort ( $12 \%$ of patients had melanoma). The same effect was not observed

Table 2 Results of the Dunnet tests and the log rank test for patients with brain tumors and their control groups

\begin{tabular}{lcc}
\hline Group comparison & Number of sICHs within the cohort & p value \\
\hline GBM with AF (37\% on AC) vs. GBM without AF and AC (control) (Dunnet-test) & 5 (2 under anticoagulation) vs. 6 & 0.991 \\
GBM with AF (37\% on AC) vs. Stroke patients with AF on AC (control) (Dunnet-test) & 5 (2 under anticoagulation) vs. 4 & 0.123 \\
All three groups (log-rank-test) & 5 (3 under anticoagulation) vs. 6 & 0.076 \\
MET with AF (46\% on AC) vs. MET without AF and AC (control) (Dunnet-test) & 5 (3 under anticoagulation) vs. 3 & 0.253 \\
MET with AF (46\% on AC) vs. Stroke patients with AF on AC (control) (Dunnet-test) & & 0.11 \\
All three groups (log-rank-test) & &
\end{tabular}

$A C$ full anticoagulation, $A F$ atrial fibrillation, $G B M$ glioblastoma, $M E T$ brain metastases, $S I C H$ symptomatic intracranial hemorrhage 
for renal cell carcinoma. A possible confounding factor to the incidence of hemorrhage is the radiation protocol as hemorrhage is a known complication of stereotactic radiosurgery [26, 27]. In combination with immunotherapy or targeted therapy, radiosurgery is increasingly established as the standard of care and replacing whole brain radiotherapy for patients with brain metastases [28, 29]. However, as we could not perform a multivariate analysis, we cannot exclude confounding factors such as radiotherapy, the number and size of metastases, antiangiogenic therapy or immunotherapy on the incidence of ICH.

With a median $\mathrm{CHA}_{2} \mathrm{DS}_{2} \mathrm{VASc}$-Score of 3 , the risk of stroke is expected to be about $3 \%$ per year in our cohorts [30]. In fact, the incidence of stroke was as high as $10 \%$ in our study, probably because 54\% (brain metastases) and 63\% (glioblastoma) of patients were not sufficiently anticoagulated and because of the inherently higher risk of patients with cancer to develop arterial and venous thromboembolism [31].

Obvious limitations of our analysis are the retrospective nature which carries potential distortions. Firstly, a lot of the initially screened patients had to be excluded to fit the matching and follow-up criteria and due to missing data. Secondly, AC for $\mathrm{AF}$ was usually given per local standard if the individual presumed risk for bleeding was not increased. Thirdly, a matching process had to be implemented because the extraction of all available patient data would not have been feasible within a reasonable time frame and fourthly the median follow-up was just under 9 months. Still, the overall size of the cohort $(\mathrm{N}=86)$ is acceptable as the largest reported cohorts to date included 133 and 107 patients $[12,16]$. Furthermore, we managed to build well-matched cohorts using the Propensity Score and were able to also include a cohort of patients without brain tumors that were anticoagulated. Secondly, only a total of $37 \%$ of patients in the glioblastoma group and $46 \%$ of patients in the brain metastases group received full anticoagulation while $31 \%$ respectively $19 \%$ were on prophylactic anticoagulation. While this might weaken the effect of anticoagulation on the bleeding risk, it is also a valuable insight into the existing clinical practice with doctors hesitating to prescribe anticoagulation in patients with brain tumors although recent data suggests that this is safe at least for adequately treated brain metastases [17].

In conclusion, patients with both glioblastoma and metastatic brain tumors and AF did receive prophylactic anticoagulation in $37 \%$ and $46 \%$ in our large institutional database, most likely due to perceived increased risk of intracranial bleeding. In those patients that did receive prophylactic anticoagulation we could not demonstrate an increased incidence of ICH compared to patients with brain tumors and no anticoagulation or patients on anticoagulation that had no brain tumor. In GBM and MET patients with AF and high risk of embolic stroke a sufficient anticoagulation according to the $\mathrm{CHA}_{2} \mathrm{DS}_{2}$ VASc-Score might still be warranted.
Supplementary Information The online version contains supplementary material available at https://doi.org/10.1007/s11060-021-03716-8.

Author contributions All authors contributed to the study conception and design and had an essential part in caring for the patients whose data was used in this manuscript. Data collection and analysis were performed by SB, MO and DW. Additional datasets were provided by SL, ML, TR, AB and AW. The first draft of the manuscript was written by $\mathrm{SB}$ and all authors commented on previous versions of the manuscript. All authors read and approved the final manuscript.

Funding Open Access funding enabled and organized by Projekt DEAL. No funding was received to assist with the preparation of this manuscript.

Availability of data and material The datasets generated during and analyzed during the current study are available from the corresponding author on reasonable request.

\section{Compliance with ethical standards}

Conflict of interest Outside this study, Dr. Nagel reports personal fees from Brainomix, Boehringer Ingelheim and BMS Pfizer and grants from Cerenovus. Dr. Rizos reports consulting honoraria, speakers' honoraria and travel support from Bristol-Myers Squibb/Pfizer, Boehringer-Ingelheim, Bayer HealthCare and DaichiiSankyo, outside of the present work. The other authors have stated explicitly that there are no conflict of interest in connection with this article.

Ethical approval Inclusion of patients into this analysis is covered by a local Heidelberg ethics vote (No. S307/2019).

Open Access This article is licensed under a Creative Commons Attribution 4.0 International License, which permits use, sharing, adaptation, distribution and reproduction in any medium or format, as long as you give appropriate credit to the original author(s) and the source, provide a link to the Creative Commons licence, and indicate if changes were made. The images or other third party material in this article are included in the article's Creative Commons licence, unless indicated otherwise in a credit line to the material. If material is not included in the article's Creative Commons licence and your intended use is not permitted by statutory regulation or exceeds the permitted use, you will need to obtain permission directly from the copyright holder. To view a copy of this licence, visit http://creativecommons.org/licenses/by/4.0/.

\section{References}

1. Ostrom QT, Cioffi G, Gittleman H, Patil N, Waite K, Kruchko C, Barnholtz-Sloan JS (2019) CBTRUS statistical report: primary brain and other central nervous system tumors diagnosed in the United States in 2012-2016. Neuro-oncology 21(Supplement_5):v1-v100. https://doi.org/10.1093/neuonc/ noz150

2. Barnholtz-Sloan JS, Sloan AE, Davis FG, Vigneau FD, Lai P, Sawaya RE (2004) Incidence proportions of brain metastases in patients diagnosed (1973 to 2001) in the Metropolitan Detroit Cancer Surveillance System. J Clin Oncol 22(14):2865-2872. https://doi.org/10.1200/JCO.2004.12.149

3. Yust-Katz S, Mandel JJ, Wu J, Yuan Y, Webre C, Pawar TA, Lhadha HS, Gilbert MR, Armstrong TS (2015) Venous 
thromboembolism (VTE) and glioblastoma. J Neurooncol 124(1):87-94. https://doi.org/10.1007/s11060-015-1805-2

4. Go AS, Hylek EM, Phillips KA, Chang Y, Henault LE, Selby JV, Singer DE (2001) Prevalence of diagnosed atrial fibrillation in adults: national implications for rhythm management and stroke prevention: the AnTicoagulation and Risk Factors in Atrial Fibrillation (ATRIA) Study. JAMA 285(18):2370-2375. https://doi. org/10.1001/jama.285.18.2370

5. Thaler J, Ay C, Kaider A, Reitter EM, Haselbock J, Mannhalter C, Zielinski C, Marosi C, Pabinger I (2014) Biomarkers predictive of venous thromboembolism in patients with newly diagnosed high-grade gliomas. Neuro-oncology 16(12):1645-1651. https:// doi.org/10.1093/neuonc/nou106

6. Edwin NC, Khoury MN, Sohal D, McCrae KR, Ahluwalia MS, Khorana AA (2016) Recurrent venous thromboembolism in glioblastoma. Thromb Res 137:184-188. https://doi.org/10.1016/j. thromres.2015.11.027

7. Perry JR (2012) Thromboembolic disease in patients with highgrade glioma. Neuro-oncology 14(Suppl 4):iv73-iv80. https://doi. org/10.1093/neuonc/nos 197

8. Zwicker JI, Karp Leaf R, Carrier M (2016) A meta-analysis of intracranial hemorrhage in patients with brain tumors receiving therapeutic anticoagulation. J Thromb Haemost 14(9):1736-1740. https://doi.org/10.1111/jth.13387

9. Timp JF, Braekkan SK, Versteeg HH, Cannegieter SC (2013) Epidemiology of cancer-associated venous thrombosis. Blood 122(10):1712-1723. https://doi.org/10.1182/blood-2013-04460121

10. Pan E, Tsai JS, Mitchell SB (2009) Retrospective study of venous thromboembolic and intracerebral hemorrhagic events in glioblastoma patients. Anticancer Res 29(10):4309-4313

11. Ening G, Osterheld F, Capper D, Schmieder K, Brenke C (2015) Risk factors for glioblastoma therapy associated complications. Clin Neurol Neurosurg 134:55-59. https://doi.org/10.1016/j.cline uro.2015.01.006

12. Mantia C, Uhlmann EJ, Puligandla M, Weber GM, Neuberg D, Zwicker JI (2017) Predicting the higher rate of intracranial hemorrhage in glioma patients receiving therapeutic enoxaparin. Blood 129(25):3379-3385. https://doi.org/10.1182/blood-2017$02-767285$

13. Mandybur TI (1977) Intracranial hemorrhage caused by metastatic tumors. Neurology 27(7):650-655. https://doi.org/10.1212/ wnl.27.7.650

14. Hsieh MJ, Lu CH, Tsai NW, Lui CC, Chuang YC, Huang CR, Chen SF, Chang CC, Chang HW, Chang WN (2009) Prediction, clinical characteristics and prognosis of intracerebral hemorrhage in hepatocellular carcinoma patients with intracerebral metastasis. J Clin Neurosci 16(3):394-398. https://doi.org/10.1016/j. jocn.2008.05.010

15. Alvarado G, Noor R, Bassett R, Papadopoulos NE, Kim KB, Hwu WJ, Bedikian A, Patel S, Hwu P, Davies MA (2012) Risk of intracranial hemorrhage with anticoagulation therapy in melanoma patients with brain metastases. Melanoma Res 22(4):310 315. https://doi.org/10.1097/CMR.0b013e328353efd8

16. Donato J, Campigotto F, Uhlmann EJ, Coletti E, Neuberg D, Weber GM, Zwicker JI (2015) Intracranial hemorrhage in patients with brain metastases treated with therapeutic enoxaparin: a matched cohort study. Blood 126(4):494-499. https://doi. org/10.1182/blood-2015-02-626788

17. Lin RJ, Green DL, Shah GL (2018) Therapeutic anticoagulation in patients with primary brain tumors or secondary brain metastasis. Oncologist 23(4):468-473. https://doi.org/10.1634/theoncolog ist.2017-0274

18. Rojas-Hernandez CM, Oo TH, Garcia-Perdomo HA (2017) Risk of intracranial hemorrhage associated with therapeutic anticoagulation for venous thromboembolism in cancer patients: a systematic review and meta-analysis. J Thromb Thrombolysis 43(2):233-240. https://doi.org/10.1007/s11239-016-1434-4

19. Horstmann S, Rizos T, Saribas M, Efthymiou E, Rauch G, Veltkamp R (2015) Cognitive impairment is not a predictor of failure to adhere to anticoagulation of stroke patients with atrial fibrillation. Cerebrovasc Dis 39(5-6):325-331. https://doi. org/10.1159/000381728

20. Austin PC (2011) An introduction to propensity score methods for reducing the effects of confounding in observational studies. Multivar Behav Res 46(3):399-424. https://doi.org/10.1080/00273 171.2011.568786

21. Chukwueke UN, Wen PY (2019) Use of the Response Assessment in Neuro-Oncology (RANO) criteria in clinical trials and clinical practice. CNS Oncol 8(1):CNS28. https://doi.org/10.2217/ cns-2018-0007

22. Chinot OL, Wick W, Mason W, Henriksson R, Saran F, Nishikawa R, Carpentier AF, Hoang-Xuan K, Kavan P, Cernea D, Brandes AA, Hilton M, Abrey L, Cloughesy T (2014) Bevacizumab plus radiotherapy-temozolomide for newly diagnosed glioblastoma. N Engl J Med 370(8):709-722. https://doi.org/10.1056/NEJMo a1308345

23. Kidwell CS, Wintermark M (2008) Imaging of intracranial haemorrhage. Lancet Neurol 7(3):256-267. https://doi.org/10.1016/ S1474-4422(08)70041-3

24. R Core Team (2020) R: a language and environment for statistical computing

25. Saran F, Chinot OL, Henriksson R, Mason W, Wick W, Cloughesy T, Dhar S, Pozzi E, Garcia J, Nishikawa R (2016) Bevacizumab, temozolomide, and radiotherapy for newly diagnosed glioblastoma: comprehensive safety results during and after first-line therapy. Neuro-oncology 18(7):991-1001. https://doi.org/10.1093/ neuonc/nov300

26. Suzuki H, Toyoda S, Muramatsu M, Shimizu T, Kojima T, Taki W (2003) Spontaneous haemorrhage into metastatic brain tumours after stereotactic radiosurgery using a linear accelerator. J Neurol Neurosurg Psychiatry 74(7):908-912. https://doi.org/10.1136/ jnnp.74.7.908

27. Soffietti R, Abacioglu U, Baumert B, Combs SE, Kinhult S, Kros JM, Marosi C, Metellus P, Radbruch A, Villa Freixa SS, Brada M, Carapella CM, Preusser M, Le Rhun E, Ruda R, Tonn JC, Weber DC, Weller M (2017) Diagnosis and treatment of brain metastases from solid tumors: guidelines from the European Association of Neuro-Oncology (EANO). Neuro-oncology 19(2):162-174. https ://doi.org/10.1093/neuonc/now241

28. Lauko A, Rauf Y, Ahluwalia MS (2020) Medical management of brain metastases. Neurooncol Adv 2(1):vdaa015. https://doi. org/10.1093/noajnl/vdaa015

29. Suh JH, Kotecha R, Chao ST, Ahluwalia MS, Sahgal A, Chang EL (2020) Current approaches to the management of brain metastases. Nat Rev Clin Oncol 17(5):279-299. https://doi.org/10.1038/ s41571-019-0320-3

30. Lip GY, Nieuwlaat R, Pisters R, Lane DA, Crijns HJ (2010) Refining clinical risk stratification for predicting stroke and thromboembolism in atrial fibrillation using a novel risk factorbased approach: the euro heart survey on atrial fibrillation. Chest 137(2):263-272. https://doi.org/10.1378/chest.09-1584

31. Streiff MB (2016) Thrombosis in the setting of cancer. Hematol Am Soc Hematol Educ Program 2016(1):196-205. https://doi. org/10.1182/asheducation-2016.1.196

Publisher's Note Springer Nature remains neutral with regard to jurisdictional claims in published maps and institutional affiliations. 